\title{
Lung transplantation on cardiopulmonary support: Venoarterial extracorporeal membrane oxygenation outperformed cardiopulmonary bypass
}

Fabio Ius, MD, ${ }^{\mathrm{a}}$ Christian Kuehn, MD, ${ }^{\mathrm{a}}$ Igor Tudorache, MD, ${ }^{\mathrm{a}}$ Wiebke Sommer, MD, ${ }^{\mathrm{a}}$ Murat Avsar, MD, Dietmar Boethig, MD, ${ }^{\mathrm{a}}$ Thomas Fuehner, MD, ${ }^{\mathrm{b}}$ Jens Gottlieb, MD, ${ }^{\mathrm{b}}$ Marius Hoeper, MD, ${ }^{\mathrm{b}}$

Axel Haverich, MD, ${ }^{a}$ and Gregor Warnecke, $\mathrm{MD}^{\mathrm{a}}$

Objectives: Patients requiring extracorporeal cardiorespiratory support during lung transplantation can be treated with conventional cardiopulmonary bypass (CPB) or venoarterial extracorporeal membrane oxygenation (ECMO). In a retrospective analysis, we compared the postoperative course and outcomes of patients treated using these approaches.

Methods: Between August 2008 and September 2011, 92 consecutive patients underwent lung transplantation with extracorporeal support (CPB group, $n=46$; and, since February 2010, ECMO group, $n=46$ ) at our institution. We evaluated survival, secondary organ failure, bleeding complications, and the need for blood and platelet transfusions in these 2 patient populations.

Results: Intraoperatively, the CPB group required more packed red blood cell transfusions (12 \pm 11 vs $7 \pm 9 \mathrm{U}$; $P=.01)$ and platelet concentrates $(2.5 \pm 1.6$ vs $1.5 \pm 1 \mathrm{U} ; P<.01)$ than the ECMO group. In-hospital mortality $(39 \%$ vs $13 \% ; P=.004)$, the need for hemodialysis $(48 \%$ vs $13 \% ; P<.01)$, and new postoperative ECMO support $(26 \%$ vs $4 \% ; P<.01)$ were greater in the CPB group than in the ECMO group, respectively. After propensity score analysis, multivariate analysis identified retransplantation (odds ratio, 7; 95\% confidence interval, $1-43 ; P=.034$ ) and transplantation with $\mathrm{CPB}$ support (odds ratio, 4.9; 95\% confidence interval, 1.2-20; $P=.026)$ as independent risk factors for in-hospital mortality. The survival rate at 3,9 , and 12 months was $70 \%, 59 \%$, and $56 \%$ in the CPB group and $87 \%, 81 \%$, and $81 \%$ in the ECMO group $(P=.004)$.

Conclusions: Intraoperative ECMO allows for better periprocedural management and reduced postoperative complications and confers a survival benefit compared with CPB, mainly because of lower in-hospital mortality. It is now the standard of care in our lung transplantation program. (J Thorac Cardiovasc Surg 2012;144:1510-6)

Cardiopulmonary bypass (CPB) is currently the standard method for intraoperative support of hemodynamics and respiratory function in lung transplantation. ${ }^{1}$ However, its use could be associated with a greater intra- and postoperative risk of bleeding owing to full heparinization and a greater incidence of primary graft dysfunction (PGD) from the consequences of the systemic inflammatory response. ${ }^{2-5}$

Extracorporeal membrane oxygenation (ECMO) might present as an alternative to CPB. The benefits of preoperative ECMO support as a bridge to transplantation ${ }^{6-8}$ and

From the Department of Cardiothoracic, Transplant, and Vascular Surgery ${ }^{\mathrm{a}}$ and Department of Respiratory Medicine, ${ }^{\text {b }}$ Hannover Medical School, Hannover, Germany.

Disclosures: Dr Hoeper disclosed a financial relationship with Maquet for lecture fees. All other authors have nothing to disclose with regard to commercial support. F.I. and C.K. contributed equally and share first authorship.

Received for publication Feb 5, 2012; revisions received April 28, 2012; accepted for publication July 31, 2012; available ahead of print Sept 3, 2012.

Address for reprints: Gregor Warnecke, MD, Department of Cardiothoracic, Transplant and Vascular Surgery, Hannover Medical School, Carl-Neuberg Strasse 1, Hannover 30625, Germany (E-mail: warnecke.gregor@mh-hannover.de).

$0022-5223 / \$ 36.00$

Copyright (C) 2012 by The American Association for Thoracic Surgery http://dx.doi.org/10.1016/j.jtcvs.2012.07.095 postoperative ECMO support as rescue therapy for patients with PGD $^{9,10}$ have been widely demonstrated. Recently, the use of ECMO has also been extended to intraoperative support. ${ }^{11-13}$ Lower heparin doses, the lack of a venous reservoir, and additional suction lines with their air-blood interface could reduce the complications associated with CPB. Moreover, ECMO is more versatile owing to the possibility of prolonging hemodynamic and respiratory support, allowing better postoperative hemodynamic and respiratory management in patients at high risk of developing PGD.

With these considerations, since the beginning of 2010, we have changed our routine intraoperative protocol from CPB to venoarterial ECMO. In the present study, we compared the outcomes of patients who underwent transplantation on $\mathrm{CPB}$ with the outcomes of those who underwent transplantation on venoarterial ECMO support.

\section{METHODS \\ Patients}

Between August 2008 and September 2011, 319 patients underwent lung transplantation at our institution. Of these 319 patients, $211(66 \%)$ underwent transplantation off-pump, $10(3 \%)$ with venovenous ECMO 


\section{Abbreviations and Acronyms \\ $\mathrm{COPD}=$ chronic obstructive pulmonary disease \\ $\mathrm{CPB}=$ cardiopulmonary bypass \\ $\mathrm{ECMO}=$ extracorporeal membrane oxygenation \\ ICU = intensive care unit \\ iLA = interventional lung assistance with the NovaLung \\ PGD = primary graft dysfunction \\ PRBC $=$ packed red blood cell}

support; 46 (14\%) with CPB support (CPB group); and 52 (16\%) with venoarterial ECMO support (ECMO group). Of the ECMO group, 6 patients who underwent transplantation before February 2010 were excluded from the present study. Before February 2010, CPB was our standard supporting technique, and these 6 ECMO patients might have represented a subgroup selected because of potentially confounding variables. No statistically significant difference was seen in the pre- and postoperative morbidity or mortality among the ECMO patients transplanted before and after February 2010. The records of the 46 CPB and 46 ECMO patients were retrospectively reviewed. The pre-, intra-, and postoperative and follow-up results between the CPB and ECMO groups were compared. Follow-up ended on November 30, 2011 and was $100 \%$ complete.

Pulmonary hypertension as the indication for transplantation included patients with idiopathic pulmonary hypertension, chronic pulmonary embolism, pulmonary veno-occlusive disease, congenital heart disease with Eisenmenger disease, and systemic scleroderma. The risk of cytomegalovirus infection was defined as low, if both donor and recipient were negative for anticytomegalovirus IgG antibodies or intermediate in donor-positive/ recipient-positive or donor-negative/recipient-positive settings. The risk was considered high in the donor-positive/recipient-negative setting. Urgency listing status, according to the Eurotransplant criteria, and PGD scores at 24 hours, according to the guidelines of the International Society for Heart and Lung Transplantation Working Group on PGD, ${ }^{14}$ were recorded. If intraoperative ECMO support was directly extended postoperatively, the patients were classified as requiring postoperative ECMO support. However, patients who had been intraoperatively weaned from CPB or ECMO but thereafter required new ECMO or interventional lung assistance with the NovaLung (iLA; NovaLung GmbH, Hechingen, Germany) were classified as requiring secondary ECMO/iLA implantation. Rejection was defined as the need for at least 1 steroid pulse therapy in the presence of unexplained worsening of lung function and gas exchange and an increase in inflammatory parameters. The mean postoperative duration of mechanical ventilation and the mean intensive care unit (ICU) stay were calculated after censoring the patients who had died early ( $<30$ days).

The hospital ethical committee approved the present retrospective study and waived the need for patient consent.

\section{CPB and ECMO Implant Techniques}

CPB was instituted by cannulating the ascending aorta or common femoral artery and, for venous access, the right atrium or femoral vein. Before cannulation, $400 \mathrm{IU}$ heparin $/ \mathrm{kg}$ body weight was administered. The target activated clotting time during CPB was longer than 400 seconds. After weaning from $\mathrm{CPB}$, protamine was given to antagonize the heparin. The CPB system consisted of the (1) Stöckert S III roller pump (Stöckert, Munich, Germany); (2) Apex (Sorin Biomedica, Saluggia, Italy), Capiox (Terumo Cardiovascular Systems Corp, Ann Arbor, Mich), or the Trillium Affinity (Medtronic Inc, Minneapolis, Minn) oxygenators (membrane surface area, 2.0, 0.5, and $2.5 \mathrm{~m}^{2}$, respectively); and (3) Medos venous reservoir and heparin-coated tubing system (Medos AG, Stolberg, Germany). The priming volume was usually $1400 \mathrm{~mL}$.
Since February 2010, ECMO has been used during lung transplantation instead of CPB. After a single bolus of $5000 \mathrm{IU}$ of unfractionated heparin, ECMO was instituted by percutaneous cannulation of the common femoral vein and artery, with a 20F to 24F FemTrak venous cannula (Edwards Lifesciences, Irvine, Calif) and a $15 \mathrm{~F}$ to $17 \mathrm{~F}$ NovaPort arterial cannula (NovaLung $\mathrm{GmbH}$ ). In patients in whom ECMO support had been planned to be continued postoperatively, an additional $6 \mathrm{~F}$ introducer sheath (Cordis Corp, Miami, Fla) was inserted into the femoral artery distal from the NovaLung cannula and connected to the arterial branch of the ECMO circuit for antegrade leg perfusion. The ECMO system consisted of a Maquet Rotaflow centrifugal pump and PLS Set with the Quadrox polymethylpentene membrane oxygenator (membrane oxygenator area, $1.8 \mathrm{~m}^{2}$; Maquet Cardiopulmonary AG, Hirrlingen, Germany). The priming volume was usually 800 $\mathrm{mL}$. A half dose of protamine (2500 IU) was given to antagonize heparin after intraoperative ECMO weaning. In those patients in whom ECMO support was extended postoperatively, neither protamine nor additional heparin was administered for a maximum of 48 hours after surgery. Thereafter, the activated clotting time was maintained between 160 and 180 seconds by continuous infusion of unfractionated heparin.

\section{Statistical Analysis}

Data were collected and analyzed retrospectively. SPSS, version 20.0 (SPSS, Chicago, Ill) was used to perform the data analysis. The primary endpoint was in-hospital mortality, and the secondary endpoint was postoperative morbidity. Categorical and continuous variables are summarized as percentages and mean \pm standard deviation, respectively. The independent samples Student $t$ test or the nonparametric Mann-Whitney $U$-test and the $\chi^{2}$ test or Fisher's exact test were used for groupwise comparisons of continuous and categorical variables, respectively, and to find the preoperative univariate associations with the primary endpoint. The $P$ values were 2 tailed. For a subset of 75 patients with complete data sets, propensity matching was used to provide a more valid comparison between groups. Propensity scores representing the estimated probabilities of patients receiving either $\mathrm{CPB}$ or ECMO were developed using 13 observed baseline preoperative covariates in a logistic regression model with intraoperative support type (CPB vs ECMO) as the dependent variable (female gender, chronic renal failure, listing grade, cytomegalovirus risk, pulmonary fibrosis, pulmonary hypertension, retransplantation, age at transplantation, systolic pulmonary pressure, forced expiratory volume in 1 second, forced vital capacity in 1 second [percentage of predicted], preoperative ECMO implant, and preoperative oxygen partial pressure). After propensity matching, multivariate analysis, using a forward stepwise logistic regression model, was performed to identify the preoperative independent predictors of in-hospital mortality. The model was constructed to include the preoperative risk factors with univariate $P$ values $<.2$. Model calibration was evaluated using the Hosmer-Lemeshow test for the goodness-of-fit statistic. The results are reported as odds ratios with $95 \%$ confidence intervals and the relevant $P$ value. Survival estimates and freedom from acute graft rejection at follow-up were calculated using the Kaplan-Meier productlimit method.

\section{RESULTS}

Preoperative Patient Characteristics

Since August 2008, 46 patients have undergone transplantation with CPB support, and, since February 2010, an additional 46 patients have undergone transplantation with ECMO support.

The ECMO group had a greater prevalence of pulmonary hypertension as the indication for transplantation, admission to the ICU before transplantation, a preoperative need for venoarterial ECMO support as a bridge to lung 
transplantation, and, hence, a greater preoperative risk of PGD and mortality after lung transplantation. ${ }^{15,16}$ In contrast, the CPB patients had a lower forced expiratory volume in 1 second, which could have been related to the greater prevalence of chronic obstructive pulmonary disease (COPD) (Table 1).

During the study period, the following changes in transplant management were introduced at our institution: (1)

TABLE 1. Preoperative patient characteristics

\begin{tabular}{|c|c|c|c|}
\hline Variable & $\begin{array}{c}\text { CPB } \\
(n=46) \\
\end{array}$ & $\begin{array}{r}\text { ECMO } \\
(\mathrm{n}=46) \\
\end{array}$ & $\begin{array}{c}P \\
\text { value }\end{array}$ \\
\hline Female gender & $18(39)$ & $26(56)$ & .09 \\
\hline Age (y) & $42.6 \pm 16.7$ & $42.8 \pm 14.4$ & .95 \\
\hline Chronic renal failure & $8(17)$ & $7(15)$ & .78 \\
\hline \multicolumn{4}{|l|}{ Blood group } \\
\hline A & $21(46)$ & $23(50)$ & .68 \\
\hline B & $6(13)$ & $7(15)$ & .76 \\
\hline $\mathrm{AB}$ & $2(4)$ & $1(2)$ & .55 \\
\hline $\mathrm{O}$ & $17(37)$ & $15(33)$ & .66 \\
\hline \multicolumn{4}{|l|}{ CMV risk } \\
\hline Low & $10(22)$ & $6(13)$ & .27 \\
\hline Intermediate & $26(56)$ & $29(63)$ & .52 \\
\hline High & $10(22)$ & $11(24)$ & .80 \\
\hline \multicolumn{4}{|l|}{ Listing grade } \\
\hline Elective & $6(10)$ & $5(11)$ & .75 \\
\hline Urgency & $11(24)$ & $7(15)$ & .29 \\
\hline High urgency & $29(63)$ & $34(74)$ & .26 \\
\hline \multicolumn{4}{|l|}{ Pathologic entity } \\
\hline COPD & $6(13)$ & $1(2)$ & .11 \\
\hline Pulmonary fibrosis & $17(37)$ & $16(34)$ & .83 \\
\hline Cystic fibrosis & $7(15)$ & $6(13)$ & .76 \\
\hline Pulmonary hypertension & $5(11)$ & $17(37)$ & .003 \\
\hline Retransplantation & $9(20)$ & $3(7)$ & .06 \\
\hline Other & $2(4) *$ & $3(7) \dagger$ & .50 \\
\hline $\begin{array}{l}\text { Systolic pulmonary artery } \\
\text { pressure }(\mathrm{mm} \mathrm{Hg})\end{array}$ & $58 \pm 32$ & $71 \pm 34$ & .08 \\
\hline $\mathrm{FEV}_{1}(\%$ predicted $)$ & $36 \pm 22$ & $49 \pm 25$ & .02 \\
\hline $\mathrm{FVC}_{1}(\%$ predicted $)$ & $42 \pm 19$ & $55 \pm 29$ & .09 \\
\hline 6-min Walk test (m) & $212 \pm 15$ & $233 \pm 115$ & .48 \\
\hline $\begin{array}{l}\text { Preoperative invasive mechanical } \\
\text { ventilation }\end{array}$ & $5(11)$ & $4(9)$ & .50 \\
\hline Preoperative ICU stay & $6(13)$ & $14(30)$ & .04 \\
\hline \multicolumn{4}{|l|}{ Preoperative ECMO/iLA } \\
\hline iLA & $2(4)$ & 0 & .49 \\
\hline Venovenous & $3(6)$ & $4(9)$ & .64 \\
\hline Venoarterial & $1(2)$ & $8(17)$ & .03 \\
\hline \multicolumn{4}{|l|}{ Donor } \\
\hline Female gender & $27(59)$ & $25(54)$ & .67 \\
\hline Age (y) & $39.7 \pm 14.3$ & $41.5 \pm 14.4$ & .56 \\
\hline Ventilation (d) & $6.1 \pm 3.8$ & $5.1 \pm 4.1$ & .28 \\
\hline $\mathrm{pO}_{2}(100 \%)$ & $377.3 \pm 125.2$ & $392.7 \pm 124.8$ & .61 \\
\hline
\end{tabular}

Data presented as mean $\pm \mathrm{SD}$ or $\mathrm{n}(\%) . C P B$, Cardiopulmonary bypass; $E C M O$, extracorporeal membrane oxygenation; $C M V$, cytomegalovirus; $C O P D$, chronic obstructive pulmonary disease; $F E V_{1}$, forced expiratory volume in 1 second; $F V C_{l}$, forced vital capacity in 1 second; $i L A$, interventional lung assistance with Novalung; $\mathrm{pO}_{2}$, partial oxygen pressure. * Langerhans cell histiocytosis in 1 and acute respiratory distress syndrome in 1 . $†$ Sarcoidosis in 2 and acute respiratory distress syndrome in 1. intraoperative ECMO instead of CPB support; (2) postoperative extension of intraoperative ECMO support; and (3) "awake" ECMO as a bridge to transplantation. ${ }^{8}$ The posttransplant immunosuppressive therapy regimen was similar in the CPB and ECMO groups and was based on a tripledrug regimen (calcineurin inhibitor, mycophenolate mofetil, which in some patients was switched to mammalian target of rapamycin inhibitor beyond postoperative week 4 , and prednisolone) without any induction therapy.

\section{Operative Data}

The indications for $\mathrm{CPB} / \mathrm{ECMO}$ implantation were not different between the CPB and ECMO patients and were categorized as either preoperatively planned for patients with pulmonary hypertension as an indication for transplantation, ECMO as a bridge to transplantation, suprasystemic systolic pulmonary pressure associated with the primary lung disease, and need for a cardiac surgery procedure or unplanned. In the latter case, the decision to use CPB/ ECMO support was taken intraoperatively, and implantation was elective if hemodynamic or respiratory instability ensued after test clamping of the right pulmonary artery at the beginning of the transplant procedure. It was considered not elective, if, although the initial clamping of the right pulmonary artery had not provoked any hemodynamic and respiratory consequences, instability ensued later during transplantation.

More ECMO implants were planned $(P=.004)$ owing to the greater prevalence of pulmonary hypertension and preoperative ECMO. More CPB patients required a bilateral thoracosternotomy (clamshell) approach $(P<.001$; Table 2$)$. In contrast to the CPB patients, of whom $45(98 \%)$ were weaned intraoperatively from CPB support, only 27 ECMO patients $(59 \%)$ were weaned intraoperatively from ECMO $(P<.01)$. The remaining 19 patients $(41 \%)(12$ with pulmonary hypertension, 4 with pulmonary fibrosis and sarcoidosis with associated pulmonary hypertension, and 1 each with retransplantation, cystic fibrosis, and acute respiratory distress syndrome) were transferred to the ICU with ECMO support (Figure 1).

Intraoperatively, the CPB patients required more packed red blood cell (PRBC) transfusions (median, $10 \mathrm{U}$; range, 058), platelet concentrates (median, 2; range, 0-7) than did the ECMO patients. Overall, the patients who underwent transplantation with a clamshell approach required more PRBC transfusions and platelet concentrates $(P=.047$ and $P=.017$, respectively).

\section{Postoperative Complications}

Postoperative morbidity was greater in the $\mathrm{CPB}$ than in the ECMO groups (Table 3). Of the CPB patients, 12 $(26 \%)$ required secondary ECMO/iLA implantation, $18 \pm$ 32 days (median, 2; range, 1-104) after lung transplantation. Secondary ECMO/iLA implantation was required for acute 
TABLE 2. Intraoperative data

\begin{tabular}{|c|c|c|c|}
\hline Variable & $\begin{array}{c}\text { CPB } \\
(n=46)\end{array}$ & $\begin{array}{l}\text { ECMO } \\
(n=46)\end{array}$ & $\begin{array}{c}P \\
\text { value }\end{array}$ \\
\hline \multicolumn{4}{|l|}{ Approach } \\
\hline Minimally invasive & $21(46)$ & $36(78)$ & .01 \\
\hline Clamshell & $24(52)$ & $10(22)$ & $<.01$ \\
\hline Planned CPB/ECMO implant & $13(28)$ & $28(61)$ & .004 \\
\hline Nonelective CPB/ECMO implant & $14(30)$ & $10(22)$ & .31 \\
\hline Single lung & $5(11)$ & $4(9)$ & .72 \\
\hline Double lung & $41(89)$ & $42(91)$ & .72 \\
\hline Postoperative va ECMO & $1(2)$ & $19(41)$ & $<.01$ \\
\hline Lung volume reduction & $12(26)$ & $8(17)$ & .31 \\
\hline Associated cardiac procedures & $3(6)$ & $2(4)$ & .64 \\
\hline $\mathrm{CABG}$ & 0 & $1(2)$ & \\
\hline Aortic valve replacement & $1(2)$ & 0 & \\
\hline Tricuspid valve repair & $1(2)$ & 0 & \\
\hline Atrial septal defect & $1(2)$ & 0 & \\
\hline Patent foramen ovale & 0 & $1(2)$ & \\
\hline \multicolumn{4}{|l|}{ Ischemic time (min) } \\
\hline Left & $518.0 \pm 151.7$ & $581.4 \pm 140.3$ & .05 \\
\hline Right & $431.9 \pm 140.3$ & $450.2 \pm 135.7$ & .55 \\
\hline Single & $495.4 \pm 150.3$ & $400.0 \pm 125.5$ & .34 \\
\hline CPB time $(\min )$ & $162 \pm 56$ & & \\
\hline \multicolumn{4}{|l|}{ Intraoperative blood products } \\
\hline PRBCs (U) & $12.2 \pm 10.9$ & $7.1 \pm 8.6$ & .02 \\
\hline $\mathrm{PC}(\mathrm{U})$ & $2.5 \pm 1.6$ & $1.5 \pm 1.0$ & $<.01$ \\
\hline FFP (U) & $7.2 \pm 6.4$ & $7.1 \pm 7.8$ & .93 \\
\hline Fibrinogen (g) & $2.09 \pm 1.9$ & $1.6 \pm 1.5$ & .18 \\
\hline $\begin{array}{l}\text { Prothrombin complex } \\
\text { concentrate }(\mathrm{U})^{*}\end{array}$ & $4.0 \pm 4.1$ & $3.7 \pm 3.4$ & .70 \\
\hline Recombinant factor VIIa (U) $\dagger$ & $0.1 \pm 0.4$ & $0.0 \pm 0.0$ & .02 \\
\hline
\end{tabular}

Data presented as mean \pm SD or n (\%). CPB, Cardiopulmonary bypass; ECMO, extracorporeal membrane oxygenation; $C A B G$, coronary artery bypass grafting; $P R B C$ s, packed red blood cells; $P C$, platelet concentrate; $F F P$, fresh frozen plasma. $*$ One unit equaled 500 UI. †One unit equaled 60,000 UI.

rejection (iLA in 2 and venovenous ECMO in 1) $59 \pm 39$ days (range, 35-104) after transplantation or for primary graft dysfunction (iLA in 2 and venoarterial ECMO in 7) $2 \pm 2$ days (range, 1-7) after transplantation. After a mean ECMO/iLA support duration of $12 \pm 10$ days, 10 patients could not be weaned from ECMO/iLA and died under support, 1 patient was weaned but died 2 months later, and 1 patient was successfully weaned and discharged 3 months later. Moreover, of these $12 \mathrm{CPB}$ patients, 11 required dialysis.

In contrast, of the 19 primary ECMO patients, who had been transferred to the ICU with ECMO support, 17 $(89 \%)$ were successfully weaned from ECMO after $5 \pm$ 3 days and survived until discharge, 1 patient was successfully weaned from ECMO but died of sepsis in-hospital 2 months later, and 1 patient died of PGD under ECMO support. Of the 27 primary ECMO patients, who had been weaned from ECMO intraoperatively, only $2(8 \%)$, who had undergone transplantation early in 2010 for pulmonary hypertension, required secondary ECMO implantation because of recurrent lung edema after extubation. Both patients were successfully weaned from ECMO support, were discharged, and survived to the last follow-up date (Figure 1).

Of the ECMO patients, $5(11 \%)$ experienced complications related to percutaneous cannulation of the femoral vessels (arteriovenous fistula in 2, type B dissection in 1, and lower limb ischemia requiring embolectomy in 2).

\section{Survival and Follow-up}

Of the CPB patients, $18(39 \%)$ died in-hospital (graft dysfunction in 11, sepsis in 5, stroke in 1, and small cell lung carcinoma in 1). In contrast, 6 ECMO patients $(13 \%$ ) died in-hospital (graft dysfunction in 1, sepsis in 4, and lung carcinoma in $1 ; P=.004$ ). Including the propensity score for ECMO selection, multivariate analysis identified the following independent risk factors for in-hospital death: retransplantation (odds ratio, 7.0; 95\% confidence interval, $1-43 ; P=.034)$; transplantation with CPB support (odds ratio, 4.9; 95\% confidence interval, 1.2-20; $P=.026$; Hosmer-Lemeshow statistic, $P=.7$ ).

For the patients surviving at hospital discharge, the mean follow-up was $18 \pm 11$ months (range, $3-40$ ). At 3, 9, and 12 months, the freedom from acute rejection was $89 \% \pm 6 \%$ versus $67 \% \pm 7 \%, 75 \% \pm 8 \%$ versus $55 \% \pm 8 \%$, and $55 \% \pm 10 \%$ versus $51 \% \pm 9 \%$ in the CPB and ECMO groups, respectively $(P=.12)$. The forced expiratory volume in 1 second (percentage of predicted) at discharge and at the last follow-up visit was $51 \pm 13$ versus $54 \% \pm$ $16 \%(P=.45)$ and $59 \% \pm 24 \%$ versus $61 \% \pm 21 \%$ $(P=.77)$ in the CPB and ECMO patients, respectively.

Six late deaths occurred, four in the CPB group (disseminated aspergillosis, pneumonia, aortic valve endocarditis, and post-transplant lymphoproliferative disorder in one each) and two in the ECMO group (cardiomyopathy of unknown origin and massive gastrointestinal bleeding in one each). At 3, 9, and 12 months, overall survival was 70\% $\pm 7 \%$ versus $87 \% \pm 5 \%, 59 \% \pm 7 \%$ versus $81 \% \pm$ $6 \%$ and $56 \% \pm 7 \%$ versus $81 \% \pm 6 \%$ in the $\mathrm{CPB}$ and ECMO patients, respectively ( $P=.004$; Figure 2 ). In contrast, survival conditional to hospital discharge was not different between the 2 groups $(96 \% \pm 3 \%$ vs $97 \% \pm 3 \%$, $96 \% \pm 3 \%$ vs $94 \% \pm 4 \%$, and $93 \% \pm 5 \%$ vs $94 \% \pm$ $4 \%$ in the CPB and ECMO patients, at 3, 9, and 12 months, respectively; $P=.42$ ). No difference was seen in survival among the CPB and ECMO patients if only patients undergoing nonelective CPB/ECMO implantation $(P=.18)$ or with COPD, cystic fibrosis, and pulmonary fibrosis as an indication for transplantation $(P=.12)$ were considered.

At 3, 9, and 12 months, survival of the off-pump patients was $96 \% \pm 1 \%, 91 \% \pm 2 \%$, and $88 \% \pm 2 \%$, respectively, and was similar to the survival of the ECMO patients $(P=.26)$ and better than the survival of the CPB patients $(P<.001)$. 


\begin{tabular}{|c|c|c|}
\hline Phase & CPB $(n=46)$ & va ECMO $(n=46)$ \\
\hline Preoperative & $\begin{array}{l}\text { va ECMO, } n=1 \\
\text { pulmonary hypertension, } n=5\end{array}$ & $\begin{array}{c}\text { va ECMO, } n=8 \\
\text { pulmonary hypertension, } n=17\end{array}$ \\
\hline Intraoperative & CPB, $n=46$ & va ECMO, $n=38$ (+ 8 preoperative) \\
\hline & patients weaned from CPB, $n=45$ & patients weaned from va $\mathrm{ECMO}, \mathrm{n}=27$ \\
\hline End of LTX & $\begin{array}{c}\text { patients on va ECMO, } \mathrm{n}=1 \\
\text { (patient not weaned and died) }\end{array}$ & $\begin{array}{c}\text { patients on va ECMO, } n=19 \\
\text { (patients weaned and survived, } n=17 \text { ) }\end{array}$ \\
\hline ICU & $\begin{array}{c}\text { secondary ECMO/iLA, } n=12 \\
\text { (patients weaned, } n=1 \text {, died, } n=11 \text { ) }\end{array}$ & $\begin{array}{c}\text { secondary ECMO/iLA, } n=2 \\
\text { (patients weaned, } n=2 \text {, died, } n=0 \text { ) }\end{array}$ \\
\hline Discharge & survivors, $n=28(61 \%)$ & survivors, $n=40(87 \%)$ \\
\hline
\end{tabular}

FIGURE 1. Detailed summary of patients undergoing lung transplantation with extracorporeal membrane oxygenation (ECMO) or cardiopulmonary bypass $(C P B)$ support at our institution. $v a$, Venoarterial; $L T x$, lung transplantation; $I C U$, intensive care unit; $i L A$, interventional lung assistance with NovaLung; $v$, venovenous.

\section{DISCUSSION}

Using ECMO instead of CPB for lung transplantation was associated with lower mortality and morbidity, with 1-year survival comparable to that reported by the International Society for Heart and Lung Transplantation Registry ( $81 \%$ in our ECMO patients and $79 \%$ in the International Society for Heart and Lung Transplantation Registry), despite the greater preoperative morbidity in the ECMO group. ${ }^{17}$ Pulmonary hypertension and preoperative ECMO support are well-recognized preoperative risk factors for mortality in lung transplantation. ${ }^{5,15,16}$ On multivariate analysis, lung transplantation with $\mathrm{CPB}$ support and retransplantation, represented an independent risk factor for in-hospital mortality.

These results have validated our new approach and further confirm the pivotal role of ECMO in the pre-, intra-, and postoperative management of patients requiring lung transplantation. Although ECMO or iLA have already been demonstrated to be valuable procedures as a bridge to lung transplantation and as postoperative rescue therapy, ${ }^{6-10}$ the role of ECMO for intraoperative cardiopulmonary support has not yet been widely investigated, ${ }^{11-13,18}$ and CPB remains the standard for intraoperative cardiopulmonary support during lung transplantation. ${ }^{1}$ Aigner and colleagues ${ }^{12}$ found shorter ICU and hospital stays and better survival rates with ECMO than with CPB. However, they used ECMO as their routine approach for cardiopulmonary support and resorted to CPB only if a concomitant cardiac procedure was planned. Thus, more severely ill patients were clustered in the CPB group. ${ }^{12}$ Bittner and colleagues ${ }^{18}$ reported a greater need for PRBC transfusions, longer operative times, a greater incidence of graft ischemia/reperfusion injury, and reduced 1-year survival in the ECMO group compared with the CPB group. However, the results could have been confounded by the relatively small case series (8 ECMO and 7 CPB patients) and by the absence of patients needing retransplantation or preoperative ECMO support. ${ }^{18}$ In contrast, the influence of a patient selection bias was significantly reduced in our study, because the decision to use CPB or ECMO was not based on differences in the indication for surgery and was not made by the surgeon in charge but resulted from a unanimous decision to change the cardiopulmonary support strategy in February 2010.

The pros and cons of CPB support during lung transplantation and its prognostic effect on postoperative outcomes have been widely discussed during previous years. ${ }^{4,19}$ Excellent survival results were reported in low-risk elective patients with COPD or cystic fibrosis, ${ }^{20-22}$ with hemodynamic and immunologic protective effects. ${ }^{19,21} \mathrm{In}$ contrast, 1-year survival rates similar to ours in CPB case series of patients with pulmonary hypertension have been reported, ${ }^{23-25}$ and $\mathrm{CPB}$ was even identified as a risk factor for PGD. ${ }^{4,23}$ Regarding the potential mechanisms explaining the negative outcome of CPB patients, of major importance could have been the greater need for blood transfusions in the CPB than in the ECMO patients, which had already been associated with transfusionrelated lung injury and PGD. ${ }^{5}$ The lower blood product use in ECMO patients, which compared favorably to previous CPB and off-pump case series, ${ }^{18,20}$ could have resulted from the reduced heparin dose, which allowed better control of hemostasis compared with CPB. The negative effect of $\mathrm{CPB}$ on blood product use and the postoperative outcomes could have been confounded by the greater prevalence of 
TABLE 3. Postoperative data

\begin{tabular}{|c|c|c|c|}
\hline Variable & $\begin{array}{c}\text { CPB } \\
(n=46)\end{array}$ & $\begin{array}{r}\text { ECMO } \\
(n=46)\end{array}$ & $\begin{array}{c}P \\
\text { value }\end{array}$ \\
\hline Rethoracotomy for bleeding & $16(35)$ & 9 (19) & .10 \\
\hline New requirement for dialysis & $22(48)$ & $6(13)$ & $<.01$ \\
\hline Vascular complications & $1(2)$ & $5(11)$ & .20 \\
\hline PGD score grade 3 & $9(21)^{*}$ & $7(15)$ & .45 \\
\hline Atrial fibrillation & $11(24)$ & $12(26)$ & .81 \\
\hline Rejection & $18(39)$ & $15(33)$ & .51 \\
\hline Stroke & $1(2)$ & $2(4)$ & .50 \\
\hline $\begin{array}{l}\text { Superficial secondary wound } \\
\text { infection }\end{array}$ & $6(13)$ & $7(15)$ & .76 \\
\hline Secondary ECMO/iLA implantation & $12(26)$ & $2(4)$ & $<.01$ \\
\hline Tracheotomy & $22(48)$ & $17(37)$ & .29 \\
\hline Ventilation time $(\mathrm{d}) \dagger$ & $21.4 \pm 28.8$ & $14.1 \pm 19.1$ & .40 \\
\hline ICU stay $(d) \dagger$ & $28.9 \pm 32.1$ & $19.1 \pm 18.4$ & .46 \\
\hline \multicolumn{4}{|l|}{ Postoperative blood products } \\
\hline PRBC (U) & $17.9 \pm 19.9$ & $12.7 \pm 22.8$ & .26 \\
\hline $\mathrm{PC}(\mathrm{U})$ & $4.8 \pm 8.8$ & $3.3 \pm 5.8$ & .35 \\
\hline FFP (U) & $17.6 \pm 34.8$ & $11.1 \pm 25.8$ & .32 \\
\hline Fibrinogen $(\mathrm{g})$ & $0.6 \pm 2.2$ & $0.5 \pm 1.7$ & .78 \\
\hline $\begin{array}{l}\text { Prothrombin complex concentrate } \\
\text { (U) } \ddagger\end{array}$ & $1.3 \pm 3.8$ & $2.7 \pm 6.9$ & .24 \\
\hline Recombinant factor VIIa (U)§ & $0.02 \pm 0.14$ & $0.02 \pm 0.151$ & .97 \\
\hline \multicolumn{4}{|l|}{$\begin{array}{l}\text { Spirometry at discharge } \\
(\% \text { predicted })\end{array}$} \\
\hline VC (L) & $49 \pm 13$ & $52 \pm 15$ & .37 \\
\hline $\mathrm{FEV}_{1}(\mathrm{~L})$ & $51 \pm 13$ & $54 \pm 16$ & .45 \\
\hline FEF $50 \%(\mathrm{~L} / \mathrm{s})$ & $64 \pm 28$ & $65 \pm 26$ & .83 \\
\hline FEF $25 \%(\mathrm{~L} / \mathrm{s})$ & $76 \pm 41$ & $71 \pm 41$ & .67 \\
\hline FEF $25 \%-75 \%(\mathrm{~L} / \mathrm{s})$ & $71 \pm 28$ & $70 \pm 29$ & .96 \\
\hline
\end{tabular}

Data presented as mean $\pm \mathrm{SD}$ or n (\%). $C P B$, Cardiopulmonary bypass; $E C M O$, extracorporeal membrane oxygenation; $P G D$, primary graft dysfunction; $i L A$, interventional lung assist Novalung; $I C U$, intensive care unit; $P R B C$ s, packed red blood cells; $P C$, platelet concentrate; $F F P$, fresh frozen plasma; $V C$, vital capacity; $F E V_{l}$, forced expiratory volume in 1 second; $F E F$, forced expiratory flow. *Data not available for 4 patients $(9 \%)$. $\dagger$ ICU survival (patients who died $\leq 30$ days were censored). $\ddagger$ One unit equaled $500 \mathrm{U}$. §One unit equaled 60,000 UI.

the clamshell approach and retransplantation in $\mathrm{CPB}$ patients. In the former case, no significant difference was seen among the CPB patients who required a clamshell or minimally invasive approach regarding intra- and postoperative PRBC, platelet concentrate, and fresh frozen plasma use. In the latter case, the greater heparin dose in the CPB patients could have eventually worsened the diffuse bleeding from pleural adhesions. Moreover, the negative effect of retransplantation on in-hospital mortality was distributed equally among the CPB and ECMO patients, with no difference between the retransplanted $\mathrm{CPB}$ and ECMO patients $(P=.8)$.

CPB seems to allow for less-versatile postoperative hemodynamic management, especially in patients with pulmonary hypertension, who are at high risk of developing PGD postoperatively. ${ }^{5,15,16}$ This was reflected by the greater need for secondary ECMO/iLA implant in the CPB than ECMO patients in our case series. Of the $9 \mathrm{CPB}$ patients who required a secondary ECMO/iLA implant for PGD, 6 had

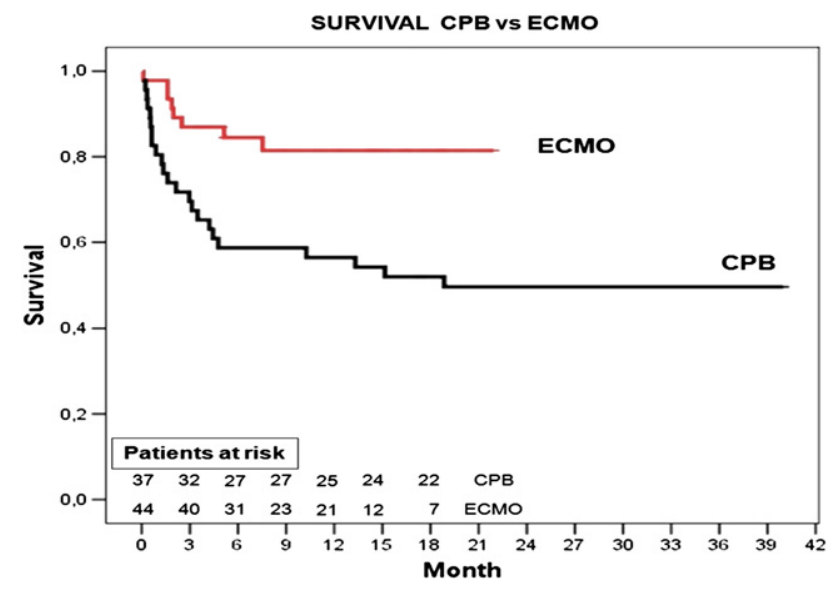

FIGURE 2. Overall survival was worse for cardiopulmonary bypass $(C P B)$ than for extracorporeal membrane oxygenation $(E C M O)$ patients $(P=.004)$, especially because of greater early (in-hospital) mortality of $\mathrm{CPB}$ patients.

presented preoperatively with pulmonary hypertension. In addition, all these patients developed acute renal failure, and 8 patients required dialysis. Extending ECMO support postoperatively, instead, allowed the blood flow to adapt to the pulmonary bed and at the same time to optimize the ventilatory and fluid management strategy by avoiding high inspiratory pressures and hemodynamic instability and eventually barotrauma and dialysis. Thus, only 2 ECMO patients required secondary ECMO implantation for delayed graft dysfunction. Both had undergone transplantation for pulmonary hypertension in February 2010 at the beginning of our experience with ECMO, and in both patients, ECMO support was initially not extended postoperatively. However, we now transfer patients with pulmonary hypertension as the indication for transplantation from the operating room to the ICU with continuous ECMO support. Such patients will not be weaned until they are fully awake and extubated. Extending ECMO support postoperatively should no longer be regarded as a complication. In contrast, it should be considered a fundamental part of a management strategy that, during the past 3 years, has led to increasing enthusiasm to perform double lung transplantation in patients with pulmonary hypertension $(3 \%$ in $2008,2 \%$ in $2009,10 \%$ in 2010 , and $6 \%$ in 2011 ) and to greatly reduce in 2011 the need for secondary ECMO implantation overall (1 [0.8\%] of 125 patients).

Finally, ECMO might reduce the proinflammatory effects of $\mathrm{CPB}$, which have already been demonstrated in cardiac surgery to provoke a systemic inflammatory response. ${ }^{2-4}$ This advantage could result from the centrifugal, instead of roller, pumps, which reduce the risk of hemolysis, ${ }^{2}$ the shorter tubing system, and avoidance of cardiotomy suction systems and venous reservoirs with their air-blood interface. Thus, ECMO reduces the risk of the development of 
systemic inflammatory response and, because it does not require full heparinization, the risk of bleeding and the subsequent need for transfusion.

\section{Study Limitations}

The following study limitations were identified. First, this was a retrospective single-center study. Second, the results could have been flawed by the poor outcomes of the CPB patients. However, because most lung transplants at our institution are performed without $\mathrm{CPB}$ or $\mathrm{ECMO}, \mathrm{CPB}$ was only used in those patients that absolutely required it for hemodynamic and respiratory reasons, causing a selection bias toward patients with a greater preoperative risk than that of patients with COPD and cystic fibrosis, in whom excellent results with CPB have been demonstrated. ${ }^{20-22}$ However, the greater preoperative risk profile of the ECMO patients compared with that of the CPB patients should have negatively influenced the outcome of the ECMO patients and not that of the CPB patients. Third, the CPB patients were transplanted before the ECMO patients in a consecutive fashion. However, in contrast to other CPB series ${ }^{20-22}$ the study period consisted of a relatively short period (3 years), with a greater incidence of patients transplanted monthly ( 2 patient $/ \mathrm{mo}$ and 2.5 patients/mo for the CPB and ECMO groups, respectively) and with an otherwise unchanged overall transplant protocol. The clamshell approach was used less often in the ECMO group than in the CPB group, in part because cannulation for ECMO was routinely performed in the groin, which did not necessitate opening the pericardium. Postoperative bleeding could thus have been reduced by the minimally invasive incisions, potentially confounding the results. Because this confounder was, however, itself caused by the change from CPB to ECMO, it could be regarded as another advantage of our ECMO strategy.

\section{CONCLUSIONS}

Compared with the CPB patients, the ECMO patients showed better survival and a better postoperative course. ECMO versatility, which allows pre-, intra-, and postoperative support, permits successful treatment of unstable patients, such as those with primary pulmonary hypertension. For these reasons, it has become our new standard of care in lung transplantation, instead of CPB, which could have a very limited role in highly selected patients who require concomitant open heart surgery.

\section{References}

1. Nagendran M, Maruthappu M, Sugand K. Should double lung transplant be performed with or without cardiopulmonary bypass? Interact Cardiovasc Thorac Surg. 2011;12:799-805.

2. Asimakopoulos G, Smith PLC, Ratnatunga CP, Taylor KM. Lung injury and acute respiratory distress syndrome after cardiopulmonary bypass. Ann Thorac Surg. 1999;68:1107-15.
3. Wan S, LeClerc JL, Vincent JL. Inflammatory response to cardiopulmonary bypass: mechanisms involved and possible therapeutic strategies. Chest. 1997;112:676-92.

4. McRae K. Con: lung transplantation should not be routinely performed with cardiopulmonary bypass. J Cardiothorac Vasc Anesth. 2000;14:746-50.

5. Barr ML, Kawut SM, Whelan TP, Girgis R, Böttcher H, Sonett J, et al. Report of the ISHLT working group on primary lung graft dysfunction, part IV: recipientrelated risk factors and markers. J Heart Lung Transplant. 2005;24:1468-82.

6. Bermudez CA, Rocha RV, Zaldonis D, Bhama JK, Crespo MM, Shigemura N, et al. Extracorporeal membrane oxygenation as a bridge to lung transplant: midterm outcomes. Ann Thorac Surg. 2011;92:1226-31.

7. Fischer S, Simon AR, Welte T, Hoeper MM, Meyer A, Tessmann R, et al. Bridge to lung transplantation with the novel pumpless interventional lung assist device NovaLung. J Thorac Cardiovasc Surg. 2006;131:719-23.

8. Fuehner T, Kuehn C, Hadem J, Wiesner O, Gottlieb J, Tudorache I, et al. Extracorporeal membrane oxygenation in awake patients as bridge to lung transplantation. Am J Respir Crit Care Med. 2012;187:699-701.

9. Mason DP, Boffa DJ, Murthy SC, Gildea TR, Budev MM, Mehta AC, et al. Extended use of extracorporeal membrane oxygenation after lung transplantation. J Thorac Cardiovasc Surg. 2006;132:954-60.

10. Fischer S, Bohn D, Rycus P, Pierre AF, de Perrot M, Waddell TK, et al. Extracorporeal membrane oxygenation after lung transplantation: analysis of the Extracorporeal Life Support Organization (ELSO registry). J Heart Lung Transplant. 2007;26:472-7.

11. Ko WJ, Chen YS, Luh SP, Lee YC, Chu SH. Extracorporeal membrane oxygenation support for single-lung transplantation in patients with primary pulmonary hypertension. Transplant Proc. 1999;31:166-8.

12. Aigner C, Wisser W, Taghavi S, Lang G, Jaksch P, Czyzewski D, et al. Institutional experience with extracorporeal membrane oxygenation in lung transplantation. Eur J Cardiothorac Surg. 2007;31:468-74.

13. Xu L, Li X, Xu M, Gao C, Zhu J, Ji B. Perioperative use of ECMO during double lung transplantation. ASAIO J. 2009;55:255-8.

14. Christie JD, Carby M, Bag R, Corris P, Hertz M, Weill D. Report of the ISHLT working group on primary lung graft dysfunction, part II: definition. A consensus statement of the International Society for Heart and Lung Transplantation. J Heart Lung Transplant. 2005;24:1454-9.

15. Kuntz CL, Hadjiliadis D, Ahya VN, Kotloff RM, Pochettino A, Lewis J, et al. Risk factors for early primary dysfunction after lung transplantation: a registry study. Clin Transplant. 2009;23:819-30.

16. Whitson BA, Nath DS, Johnson AC, Walker AR, Prekker ME, Radosevich DM, et al. Risk factors for primary graft dysfunction after lung transplantation. J Thorac Cardiovasc Surg. 2006;131:73-80

17. Christie JD, Edwards LB, Kucheryavaya AY, Benden C, Dobbels F, Kirk R, et al. The registry of the International Society for Heart and Lung Transplantation: Twenty-Eight Adult Lung and Heart-Lung Transplant Report-2011. J Heart Lung Transplant. 2011;30:1104-22.

18. Bittner HB, Binner C, Lehmann S, Kuntze T, Rastan A, Mohr FW. Replacing cardiopulmonary bypass with extracorporeal membrane oxygenation in lung transplantation operations. Eur J Cardiothorac Surg. 2007;31:462-7.

19. Marczin N, Royston D, Yacoub M. Pro: lung transplantation should be routinely performed with cardiopulmonary bypass. J Cardiothorac Vasc Anesth. 2000;14: $739-45$.

20. Szeto WY, Kreisel D, Karakousis GC, Pochettino A, Sterman DH, Kotloff RM, et al. Cardiopulmonary bypass for bilateral sequential lung transplantation in patients with chronic obstructive pulmonary disease without adverse effect on lung function or clinical outcome. J Thorac Cardiovasc Surg. 2002;124:241-9.

21. De Boer WJ, Hepkema BG, Loef BG, van der Bij W, Verschuuren EA, de Vries HJ, et al. Survival benefit of cardiopulmonary bypass support in bilateral lung transplantation for emphysema patients. Transplantation. 2002;73:1621-7.

22. Pochettino A, Augoustides JGT, Kowalchuk DA, Watcha SM, Cowie D, Jobes DR. Cardiopulmonary bypass for lung transplantation in cystic fibrosis: pilot evaluation of perioperative outcome. J Cardiothorac Vasc Anesth. 2007;21:208-11.

23. Gammie JS, Cheul Lee J, Pham SM, Keenan RJ, Weyant RJ, Hattler BG, et al. Cardiopulmonary bypass is associated with early allograft dysfunction but not death after double-lung transplantation. J Thorac Cardiovasc Surg. 1998;115:990-7.

24. Aeba R, Griffith BP, Kormos RL, Armitage JM, Gasior TA, Fuhrman CR, et al. Effect of cardiopulmonary bypass on early graft dysfunction in clinical lung transplantation. Ann Thorac Surg. 1994;57:715-22.

25. Diso D, Venuta F, Anile M, De Giacomo T, Ruberto F, Pugliese F, et al. Extracorporeal circulatory support for lung transplantation: institutional experience. Transpl Proc. 2010;42:1281-2. 